\title{
Taking the first step is to move half way
}

J Selva Andina Res Soc. 2010;1(1):1.

Journal of the Selva Andina Research Society (JSARS), is an official Journal of the Society for Researching Selva Andina (Selva Andina Research Society "SARS") of the Department of Education and Research in Biochemistry \& Microbiology (in Spanish DEI \& BM), the Peasant Academic Unit from Carmen Pampa of the Bolivian Catholic University "San Pablo", from the year 2009, is being part of the net SciELO Scientific Electronic Library Online in developing.

The net of electronic publication of journals by internet, response to the requirements of the countries from Latina America and Caribbean, as a support to the scientific communication, providing visibility and access to scientific literature, its respects the common methodology in the preparation, storage, dissemination and evaluation of scientific articles in electronic format. To date, eight Bolivian journals are being part of the SciELO Network - Bolivia: http:www.scielo.org.

Participating countries such as Argentina, Brazil, Chile, Colombia, Cuba, Spain, Portugal and Venezuela, besides SciELO "SciELO Public Health and Social Sciences"; countries that are developing as Bolivia, Mexico, Paraguay, Costa Rica, Peru, Uruguay and South Africa .

SciELO - Bolivia was made possible by the participation of different institutions like the Universidad Mayor de San Andrés, the Strategic Research Program in Bolivia, the Bolivian Catholic University, the Bolivian Association for Biomedical Journal Editors and the Vice Ministry of Science and Technology the support of the Pan American Health Organization (PAHO) Representation Bolivia.

To be part of the this project Journal of the Selva Andina Research Society SciELO-Bolivia, and meet the requirements in the criteria, policies and procedures for application, acceptance and permanence of scientific journals in the SciELO collection - Bolivia, achieving desired by the Chairman of the Board of the Supreme Council on Science and Biotechnology Society Andean jungle, leaves open the space for Undergraduate Students, Graduate, Professional, and Investigators National Public and Private Institutions around the world to submit their articles for publication, because we have recognized domestic and foreign professionals, for arbitration and guaranteeing therefore the quality of the publication.

The Chairman of the Board the Superior Council on Research \& Science and Biotechnology of the Selva Andina Research Society and the Director and Editor of the Journal of the Selva Andina Research Society with the Director General of the Peasant Academic Unit of Carmen Pampa in representation of the Peasant Academic Unit Carmen Pampa Foundation do extend this Invitation.

It Joins Directive Superior Council Research on Science and Biotechnology Director and Editor of the journal

Director General Academic Unit of Carmen Pampa (UAC-CP) 